\title{
An Investigation of Finite Element Analysis (FEA) on Piezoelectric Compliance in Ultrasonic Vibration Assisted Milling (UVAM)
}

\author{
Rasidi Ibrahim ${ }^{1}$ Haris Rachmat ${ }^{2}$, Damayanti Dida $^{2}$, Anis Radzi ${ }^{1}$ and Tatang Mulyana ${ }^{2}$ \\ ${ }^{1}$ Faculty of Mechanical Engineering and Manufacturing, University Tun Hussien Onn Malaysia, Batu Pahat, Johor \\ ${ }^{2}$ Fakulti Rekayasa Industrial, Telkom Universitas, Bandung Indonesia
}

\begin{abstract}
Finite element analysis for piezoelectric actuator has been developed in Ansys Software which are a program that can analyses and simulate the dynamic behaviour of piezoelectric. The Ultrasonic Vibration assisted Milling (UVAM) experimental having a difficulty to investigate the effect of vibration mechanism where existence of error in material, mechanism and attachment of piezoelectric thus affect the amplitude and frequency of mechanical compliance during the machining of UVAM. This paper will investigate the modelling of piezoelectric compliance and follow the procedures of FEA to accurately predict the dynamic behaviour of compliance. The parameters for simulation of piezoelectric are voltage, electromechanical coupling and frequency. The compliance mechanism is model by using SolidWorks 2014 and imported to Ansys Mechanical APDL Software were the piezoelectric are embedded on the mechanism. Modal analysis and harmonic analysis has been used in order to obtain the mode shape and displacement. The displacement of the compliance mechanism will be compare between simulation and experimental. The dynamic behaviour was discussed in simulation to study the reliability of the compliance mechanism before it safely used in UVAM.
\end{abstract}

\section{Introduction}

Ultrasonic Vibration Assisted Milling (UVAM) has been developed rapidly in the last period of twenty years ago. UVAM process consist a combination of milling operation and vibration system on the compliance mechanism. UVAM characterized by separate type cutting is a cutting method in which vibration at regular frequency within an ultrasonic range is imposed on the tool or the work piece to achieve better cutting effects $[1,2,3]$. Inside of the compliance mechanism contain of piezoelectric actuator that give a vibration to the compliance mechanism. Piezoelectric Actuator is widely use in vibration system because it has ability to generate an electric charge in response to applied mechanical stress. The piezoelectric can expansion and contraction when source of voltage applied to it. Based on the previous study the piezoelectric is a transducer that transforms part of the mechanical vibration energy into electrical energy that can be conveniently dissipated in circuit [4].

Piezoelectric is popular in recent years, due to the superiority of the piezoelectric material that have simple mechanical properties, light weight and small volume. It has been use in various application such as vibration control of rotating machine. Finite element analysis (FEA) is a method of simulating or analyzing the behaviour of engineering structures and components under a variety of conditions. In previous research, Finite element analysis is used to study the response of plate structure on which piezoelectric active devices are mounted [5]. It is an advance engineering tool to predict how a product react to real world forces, vibration, heat, fluid flow and other physical effects. Finite element analysis shows whether a product will break or work after it was designed. It is called analysis, but in the product development process, it used to predict what is going to happen when the product is used [6].

The compliance mechanism for UVAM processes has been evaluate and study in order to define the mechanical behaviour of the compliance. Nowadays, design world computer-aided engineering (CAE) tools, especially finite element analysis (FEA) plays an important role in manufacturing engineers because it can solve complex engineering problems for wide range which by simulating the design in order to improve the product designs. The mechanical equilibrium equations is apply to the complex model by integrating contributions from small and simple element shapes. Thus, mechanical and thermal responses of complex objects can be approximate through computer simulation. 


\section{Simulation Setup}

\subsection{Material and methods}

Piezoelectric is used to expand and contract the compliance after it being applied voltage and frequency on the piezoelectric. Type material of piezoelectric that has been used in this paper is PIC 151 which are modified lead zirconate - lead titanate material with high permittivity, high coupling factor and high piezoelectric charge constant. It is suitable for low power ultrasonic transducer and low frequency sound transducers [5]. The compliance mechanism is a structural steel while for piezoelectric is a discrete piezoelectric stack with two flat end plates with the material properties from PIC 151 Ceramics. The dimension of the piezoelectric are $18 \mathrm{~mm}$ width, $5 \mathrm{~mm}$ height and $5 \mathrm{~mm}$ depth. For compliance mechanism of piezoelectric was modelled in SolidWorks 2014 as shown in Figure 1 and save in SAT file and then imported in the Ansys Mechanical APDL 16.0.

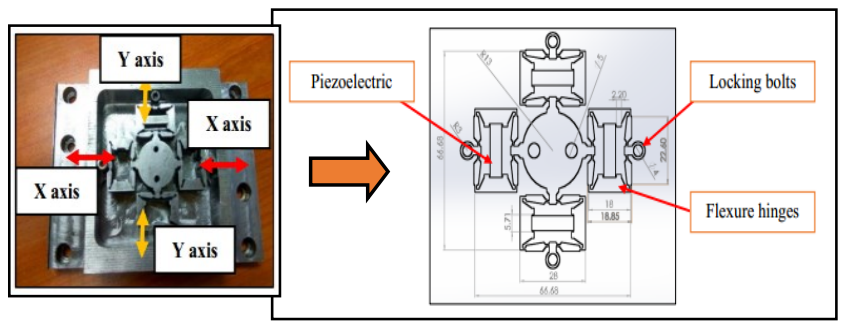

Fig. 1. Modelling of compliance mechanism and piezoelectric

The piezoelectric has been embedded on compliance in Ansys software with the voltage and electromechanical coupling as their loading condition. Element for piezoelectric are solid226 which is analysis electroelastic/piezoelectric. This model particularly has generates 69423 numbers of nodes and 37360 element. The meshing are using a smart size which are 5 fine and has been mesh at entire of the model by tetrahedral shape of meshing.

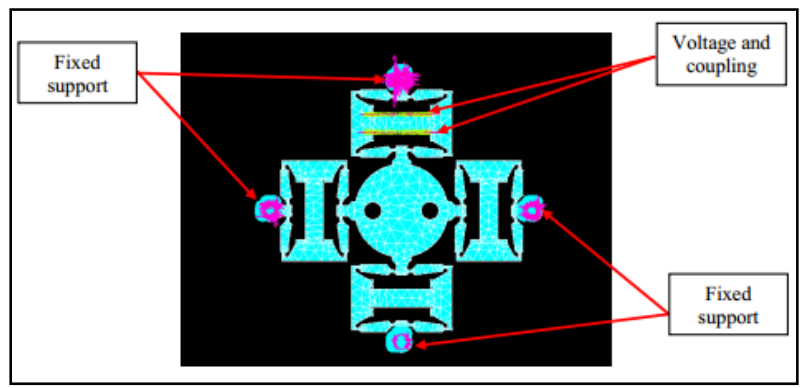

Fig. 2. Constraints (Fixed support), voltage and coupling

The constraint are zero displacement at $\mathrm{X}, \mathrm{Y}$ and $\mathrm{Z}$-axis as a locking bolt on the hole of compliance. Voltage and coupling are apply with $20 \mathrm{~V}$ at the top and $0 \mathrm{~V}$ at the bellow of the piezoelectric as shown in Figure 2. The frequency range are 0 to $18000 \mathrm{~Hz}$ with Damping of stiffness matrix multiplier piezoelectric also has been apply with $3 \times 10^{\mathrm{e}}-9$

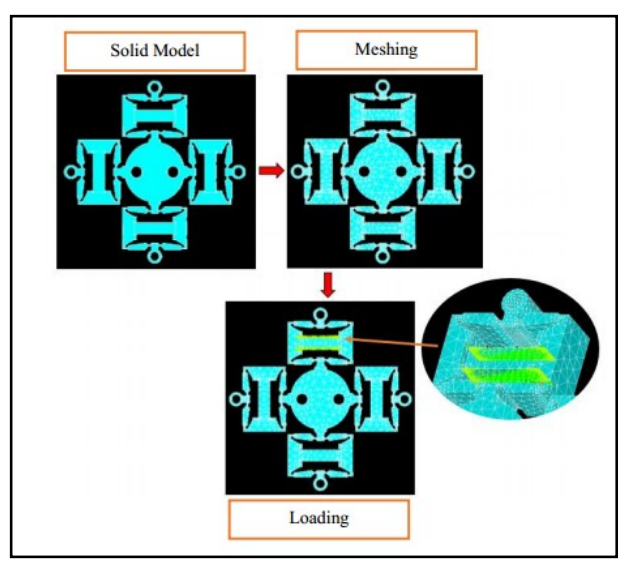

Fig. 3. Finite element analysis of compliance mechanism and piezoelectric

Figure 3 represent the compliance mechanism and piezoelectric after has been applied the meshing and loading. The solid model was transform into generation of meshing in order to create a partition space into element and nodes. The structure of the compliance are changes after it being applied the loading which are fixed constraint, voltage and electromechanical coupling.

\subsection{Experimental of UVAM}

Ultrasonic Vibration Assisted Milling (UVAM) is a machining process that has ultrasonic vibration on compliance mechanism by piezoelectric source. This machining process are suitable for cutting difficult material that has hardened surface. Figure 4 represent the illustration of vibrating worktable.

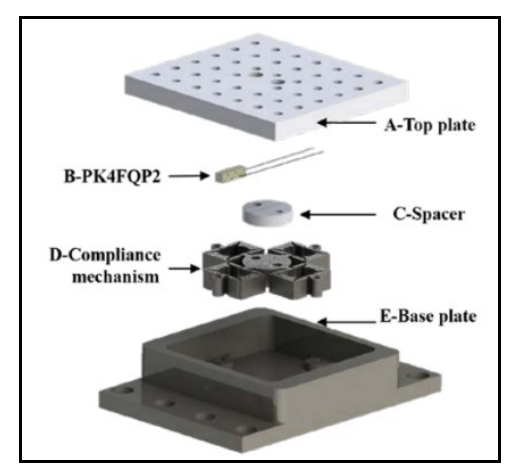

Fig. 4. Illustration of vibrating worktable.

The experiment was done in isolated room, controlled room temperature and on the granite table. The granite table is being used because it is an antivibration or vibration isolator. UVAM worktable consist of compliance mechanism and piezoelectric. Piezoelectric was embedded on the compliance mechanism as a source of the vibration to the compliance mechanism. The laser displacement was mounted on the tripod that provide stability at $90^{\circ}$ angle as shown in Figure 5 which is important for the reading accuracy. The vibrometer port was connect to PDV-100 and laser displacement was pointed to 
UVAM worktable. The function of PDV-100 is to detect the vibration at the worktable.

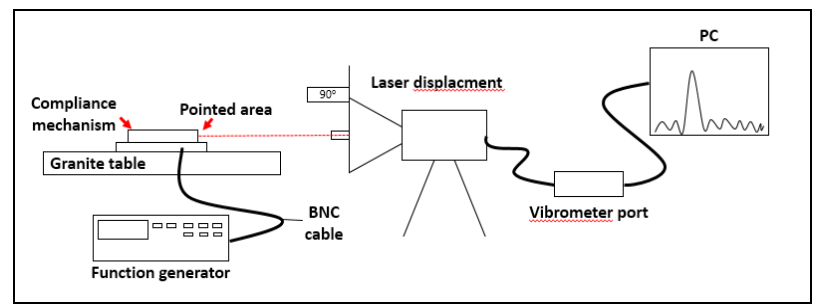

Fig. 5. Schematic diagram of instrumentation setup

Figure 5 shows the schematic diagram of instrumentation setup. Function generator are connected to compliance mechanism to produce electrical waveforms over wide of frequencies up to 1 MHz. Typical waves that produce are square, sine and triangular. In this experiment the frequency range are 0 to $18000 \mathrm{~Hz}$ to define the frequency response of the structure. Vibration amplitude of the workpiece was measured by this high-accuracy instrument delivered by the function generator.

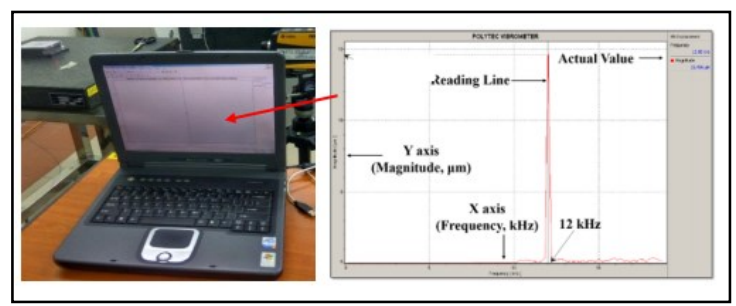

Fig. 6. Polytec Software

Polytec Vibrometer software in the PVD-100 was use to interpret the graph of displacement against frequency. The graph was set as $\mathrm{X}$-axis for frequency while the $\mathrm{Y}$-axis set as displacement or amplitude. The reading for the frequency at $\mathrm{X}$-axis limited at $18.75 \mathrm{kHz}$. The actual value of displacement on compliance will take the peak of the graph. Figure 6 shows graph obtained when measurement is being taken.

\section{Result and Discussion}

\subsection{The mode shapes of piezoelectric compliance}

Modal analysis is a technique to specify the characteristic of vibration which are mode shapes and natural frequencies of the structure compliance mechanism. This analysis is very important because the mode shapes and natural frequencies are important parameters in the design of a structure for dynamic loading conditions and for this analysis, the mode shapes and natural frequency was obtained.
Table 1. Natural frequency obtained in FEA

\begin{tabular}{|c|c|}
\hline Mode & Natural Frequency FEA (Hz) \\
\hline 1 & 317.0 \\
\hline 2 & 555.9 \\
\hline 3 & 2040.1 \\
\hline 4 & 15002.0 \\
\hline
\end{tabular}

Table 1 show the result of modal analysis of natural frequency that was determine in order to avoid resonance effects during vibration assisted machining. Natural frequency happen because of the wavelength or the speed of the piezoelectric. It is important to predict the possible failure modes in order to define the best performance.

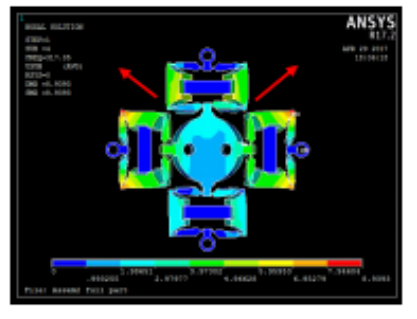

(a)

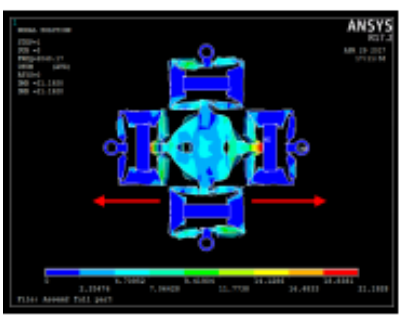

(c)

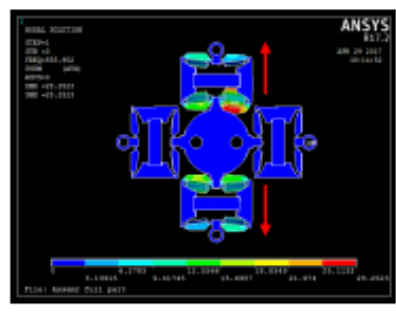

(b)

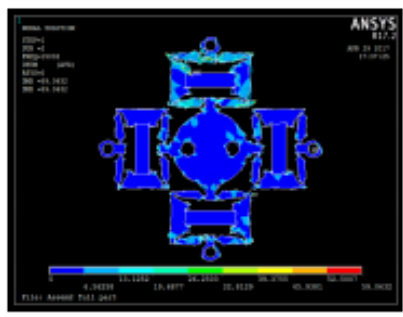

(d)
Fig. 7. Mode shapes (a) $\mathrm{F} 1=317.05 \mathrm{~Hz}$, (b) $\mathrm{F} 2=555.95 \mathrm{~Hz}$, (c) F3 $=2040.1 \mathrm{~Hz}$, (d) F4 $=15002.0 \mathrm{~Hz}$

The response of this compliance mechanism is different at each of the natural frequencies. For the first mode shape which are $\mathrm{F} 1=317.05 \mathrm{~Hz}$ (Figure $7 \mathrm{a}$ ), the deformation pattern is horizontal bending mode at $150^{\circ}$ angle of the compliance mechanism. For the second mode shape F2 $=555.95 \mathrm{~Hz}$ (Figure $7 \mathrm{~b}$ ), shows the mode shape are vertical bending (up and down) corresponding to $\mathrm{Y}$-axis of the compliance mechanism. In the Figure 7(c) indicate the third mode shape where the deformation pattern are horizontal bending (left and right).

The shape for the fourth mode shape are rupture because the movement of the compliance mechanism has a little deformation that it just move at their position only. Based on second and third mode shape, it is predicted that the maximum displacement occurs at compliance direction $\mathrm{Y}$-axis and $\mathrm{X}$-axis where the work piece is attached on the compliance. The red arrow at all Figure of the mode shape represents the direction of the mode shape action on the natural frequency. All the 
mode shape are important for the future analysis as it can predict the surface roughness by including the frequency response function. From the modal shape, it is possible to differentiate in which part the maximum value of error or deflection occurs and what range of natural frequency.

\subsection{Harmonic analysis - Displacement}

Harmonic analysis is a technique to determine the steady-state response of linear structure to loads that vary sinusoidal with time. From this analysis we can obtain the response of the piezoelectric compliance in Ultrasonic Vibrate Assisted Milling at several voltage and frequency. In additional, harmonic analysis also can determine the displacement, stress, strain, and amplitude of the piezoelectric compliance. Through this analysis, the problem such as breaking or fatigue of this structure can be overcome.

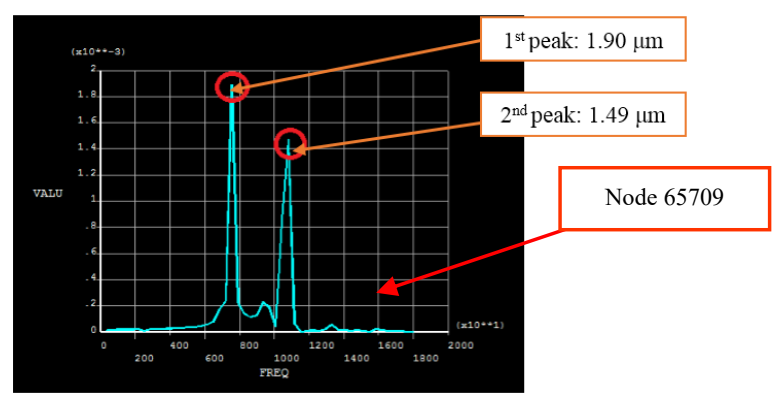

Fig. 8. Graph displacement vs frequency of compliance (Yaxis)

Based on Figure 8, the graph displacement against frequency for overall frequency from 0 to $18000 \mathrm{~Hz}$. This graph are taken at node 65709 where it located on the compliance. The node has been choosen at area above of the compliance because in experimental the workpiece are attached on the compliance to obtain the response of the compliance. The maximum displacement of compliance are $1.90 \mu \mathrm{m}$ at frequency $7560 \mathrm{~Hz}$. For the second peak of graph displacement is $1.49 \mu \mathrm{m}$ at frequency $10900 \mathrm{~Hz}$. From the graph 4.10 show that the maximum displacement on compliance occoured between $7,000 \mathrm{~Hz}$ to $110,00 \mathrm{~Hz}$.

\subsection{Comparison displacement of compliance piezoelectric between simulation and experimental}

In finding the displacement between experimental and simulation is important to correlate the result between them. This is because during machining, the displacement will affect the accuracy of the vibration of the work piece. The displacement in simulation was taken at node 65709 where it located on top of the compliance.
Table 2. Comparison of displacement compliance mechanism

\begin{tabular}{|c|c|c|c|}
\hline Readings & $\begin{array}{c}\text { Displacement } \\
\text { (Simulation), } \\
\mu \mathrm{m}\end{array}$ & $\begin{array}{c}\text { Displacement } \\
\text { (Experimental), } \\
\mu \mathrm{m}\end{array}$ & $\begin{array}{c}\text { Percentage } \\
\text { Error, \% }\end{array}$ \\
\hline 1 & 1.89 & 1.72 & 9.88 \\
\hline 2 & 1.48 & 1.23 & 20.33 \\
\hline 3 & 0.85 & 1.12 & 24.11 \\
\hline Average & 1.41 & 1.36 & 18.11 \\
\hline
\end{tabular}

Table 2 represent the comparison of displacement compliance mechanism between simulation and experimental. The readings was selected based on the 3 highest reading in the data displacement of FEA and experimental. Based on the Table 2, the value of the percentage error is slightly higher at reading 2 and 3 which is $20.33 \%$ and $24.11 \%$. However by comparing the result for the reading 1, the comparison error are acceptable. The data displacement from simulation and experimental was turn into comparison graph. Refer Figure 11 to see the correlation between simulation and experimental. All the readings has different frequency response where the compliance are displace. According to reading 1,2 and 3 , the simulation frequency are $7560 \mathrm{~Hz}, 10800 \mathrm{~Hz}$ and $10440 \mathrm{~Hz}$. While for the experimental are $18000 \mathrm{~Hz}, 15000 \mathrm{~Hz}$ and $17640 \mathrm{~Hz}$. The frequency are different because in experimental source of voltage are not directly pointing to the piezoelectric compare to simulation the source of voltage are directly through the piezoelectric. Besides that, in experimental the attachment of piezoelectric on the compliance is loose and has a gap inside the flexure hinges that might affect the frequency of the compliance. However the peak of the displacement between simulations and experimental is near similarly

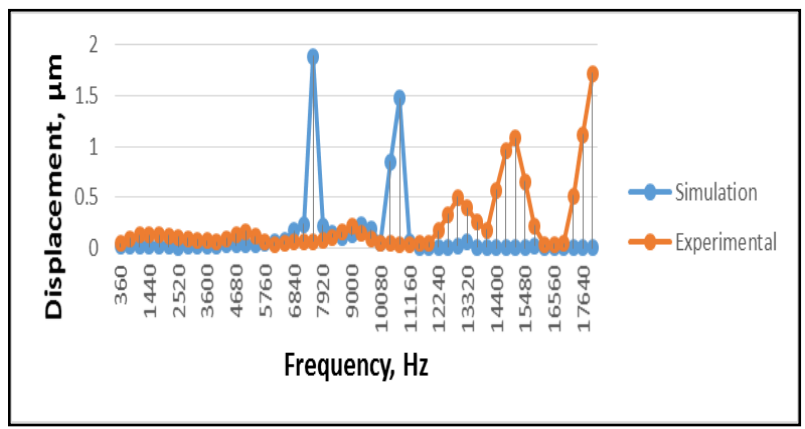

Fig. 9. Comparison graph displacement vs frequency between simulation and experimental

\section{Conclusion}

Overall of this paper was presented about a finite element analysis of compliance mechanism and piezoelectric that based on the simulation and experimental to achieve the aims and objectives. The data was presented through the Figure, Table and graph to show the trend of the data in order to correlated the results between the simulation and experimental. All the data has been analysed and discussed based on previous 
review. The displacement is important for compliance mechanism because it will affect the accuracy of the vibration of the work piece during machining. Natural frequency mode shape is a modal parameter that we can analyse and prevent the vibration problem causes by resonance.

The authors would like to express their appreciation to the Office for Research, Innovation, Commercialization and Consultancy Management (ORICC), Universiti Tun Hussein Onn Malaysia for the financial support. This work also a collaboration with FRI Telkom Univesitas Bandung, Indonesia.

\section{References}

1. Ibrahim, M. R, Rahim, Z., Rahim, E., Tobi, L, Cheng, K. and Ding, H, “ An Experimental Investigation of Cutting Temperature and Tool Wear in 2 Dimensional Ultrasonic Vibration Assisted Micro-Milling,". 3rd International Conference on Mechatronic and Mechaical Manufacturing (ICMME16)., Vol. 95, (2017).

2. Ibrahim, R., Rafai N.H., Rahim, E.A., Cheng, K.and Ding, H,"A Performance of 2 Dimensional Ultrasonic Vibration Assisted Milling in Cutting Force Reduction on Aluminium AL6061". Vol. 11. Issue 18, (2016) Pp. 11124-11128.

3. J. Kim, V. V Varadan, and V. K. Varadan, "Finite Element Modelling of Structures Including Piezoelectric Active Devices," Int. J. Numer. Methods Eng., vol. 40, no. 5, pp. 817-832, (1997).

4. Ibrahim, M. R, Rahim, E.A, ghazali, M. I, Chai, M. $\mathrm{H}$ and Goh, Z. O, "Use of finite element structural models in analyzing machine tool chatter," Finite Elem. Anal. Des., vol. 38, no. 11, pp. 1029-1046, (2002).

5. P. Technology, "Piezoelectric Ceramic Products," pp. 1-44, (2014).

6. Rachmat, H. Ibrahim, M. R and Hasan, S. B. " Design Selection of and Innovative Tool Holder for Ultrasonic Vibration Assisted Turning (IN-UVAT) using Finite Element Analysia Simulation" 7th International Conference on Mechanical \& Manufacturing Engineering, Sustainable Energy Towards Global Synergy, (ICME2016), Vol. 1831,

7. X. H. Shen, J. H. Zhang, H. Li, J. J. Wang, and X. C. Wang, "Ultrasonic vibration-assisted milling of aluminum alloy," Int. J. Adv. Manuf. Technol., vol. 63, no. 1-4, pp. 41-49, 2012

8. J. R. Baker and K. E. Rouch, "Use of finite element structural models in analyzing machine tool chatter," Finite Element Analysis and Design, vol. 38, no. 11, pp. 1029-1046, 2002
9. J. Kim, V. V Varadan, and V. K. Varadan, "Finite Element Modelling of Structures Including Piezoelectric Active Devices," Int. J. Numer. Methods Eng., vol. 40, no. 5, pp. 817-832, 1997

10. A. J. Moheimani, S.O.R., and Fleming, Piezoelectric Transducers for Vibration Control and Damping Piezoelectric Shunt Damping. 2006 